\title{
Practical Argumentation as Reasoned Advocacy
}

\author{
MARCIN LEWIŃSKI
}

ArgLab, Nova Institute of Philosophy

Universidade Nova de Lisboa

Avenida de Berna 26C, 1069-061 Lisbon

Portugal

m.lewinski@fcsh.unl.pt

\begin{abstract}
The paper offers a theoretical investigation into the sources of normativity in practical argumentation. The chief question is: Do we need objectively-minded, unbiased arguers or can we count on "good" argumentative processes in which individual biases cancel each other out? I address this question by analysing a detailed structure of practical argument and its varieties, and by discussing the tenets of a comparative approach to practical reason. I argue that given the comparative structure proposed, reasoned advocacy in argumentative activity upholds reasonableness whenever that activity is adequately designed. I propose some basic rules for such a design of practical argumentation.
\end{abstract}

Résumé: Cet article offre un examen théorique des sources de normativité dans l'argumentation pratique. La question principale qui nous occupe est la suivante: avons-nous besoin d'argumentateurs objectifs et non-biaisés ou pouvons-nous compter sur de "bons" processus argumentatifs susceptibles de neutraliser les biais individuels? Je traite d'abord cette question à travers une analyse de la structure détaillée de l'argumentation pratique et de ses variétés et ensuite par une discussion des fondements d'une approche comparative de la raison pratique. Je défends l'idée que selon la structure comparative proposée, tout plaidoyer raisonné dans une activité argumentative maintient la raisonnabilité tant que cette activité est conçue de manière appropriée. Je propose quelques règles de base pour une telle conception de l'argumentation pratique.

Keywords: advocacy, argumentation, comparativism, deliberation, polylogue, practical argument

\section{Introduction}

In a recent contribution to a book called Weighing Reasons (Lord \& Maguire, eds., 2016), Ruth Chang proposes a comparative theory of practical reason. She captures the problem and offers its basic solution at the very beginning of her chapter: 
What grounds objectively rational choice? [...] The answer I propose is what I call "comparativism." According to comparativism, comparative facts are what make a choice objectively correct; they are that in virtue of which a choice is objectively rational or what one has most or sufficient normative reason to do. (Chang, 2016, pp. 213-214)

The solution thus rests on the notion of "comparative facts" capturing basic comparison relations: better than, worse than and equally good. In a "well-formed choice situation"- "one in which there is a determinate and small set of alternatives" to choose from - it is rational to go for the alternative $\mathrm{X}$ whenever " $\mathrm{X}$ is better than $\mathrm{Y}[\mathrm{Z}$, etc.] with respect to $\mathrm{p}$, " 1 where $\mathrm{p}$ is a "covering consideration," such as beauty or efficiency (Chang, 2016 , p. 215, 217). As simple as it may seem, with all arguments laid out and all footnotes carefully filled in (Chang, 2002; 2004; Temkin, 2012), comparativism makes a comparatively strong theory of the normative grounds of practical reason.

Chang is quick to specify that she offers a theory of practical reason and not of practical reasoning: it doesn't tell us "how we should arrive at rational choice" but "instead that in virtue of which a choice is rational, however we should arrive at it" (Chang, 2016, p. 216; emphasis in original). The idea that "the correct decision procedure determines the correct ground of rational choice" (Chang, 2016, p. 216, fn. 4) is thus deemed "controversial" and abandoned.

This last move is, of course, well-known to argumentation scholars. If arguments are abstract objects existing in a Fregean realm of otherworldly ontology where their correctness is exclusively established, then argumentation theory is merely a theory of the uses of arguments, of actual processes and procedures that may bring us closer to the good arguments, defined out there. Normatively speaking, it thus becomes a theory of approximation (how might we get there, as close as we can), rather than a theory of "rational," "objective grounds" of "normative reasons."

Unsurprisingly, such philosophical views do not have much currency among communication scholars. For them, the immanent or internal (as opposed to transcendent or external) normativity of argumentation is a fundamental part of human communication. Accordingly (see Lewiński, in press), a central

\footnotetext{
${ }^{1}$ Or, in some cases, "equally good." Chang also recognises other comparative relations - such as "on a par"-which extend comparativism beyond the standard trichotomy of better than, worse than and equally good. See Chang (2002).
} 
question in argumentation theory would be: How do we align our knowledge of what a good reason is with our knowledge of how reasons get actualised in the world? For Wenzel (1990), all three perspectives on argument - that of logical product, dialectical procedure and rhetorical process - are equally relevant, "equally good" might we say, normative takes on the human practices of argument. Craig \& Tracy (1995) go a step further and find the normative grounds for communication in the very thick of communicative practices, often characterised by competing goals and the ensuing need for balanced management of communicative trade-offs. Ideals are thus always already situated rather than brought down from heavens. ${ }^{2}$ Further, to avoid simplifying discipline divisions, many philosophers share, indeed inspire, these views. Searle $(1969 ; 2001 ; 2010)$ has long promoted the view that the speech act performance in the social world is imbued with an internal deontology derived from the very semantics of speech acts and "the institution of language." In particular, in the world of conflicting individual desires and overlapping social obligations, there can be no deductive logic of practical reason-and yet there exists rationality in action (Searle, 2001). In his own way, Habermas (1984) captures this embodied normativity by defining communicative rationality as grounded in the pragmatic presuppositions governing rationalcritical discussions allowing for a free and open critical verification of arguers" "validity claims" attached to speech acts.

Goodwin (2005), discussing Habermasian ideas via Rehg's analysis, admits we might never be in a position to conclusively determine whether the norms of argument are contextually designed by arguers themselves in and through their situated argumentative transactions - or, by contrast, they simply locally specify some stable and generalizable ideas of rationality (Goodwin, 2005, esp. pp. 158-159). Her own work tilts strongly toward the first option. However, even those argumentation scholars who define normativity of argumentation in terms of universal and external philosophical ideal of critical rationality-such as pragma-dialecticians (van Eemeren \& Grootendorst, 2004) — would subscribe to the idea that: "Rational decision making is not so much a matter of making the right decision, but one of making the decision right" (Miller, 1994, p. 43; quoted in Fairclough \& Fairclough, 2012, p. 49). Whether "the correct

\footnotetext{
2 "Rather than to presuppose a philosophically derived normative ideal as a basis for the critique of practice, [our] grounded practical theory attempts to generate new and more practically relevant normative ideals through rational reconstruction of situated ideals discovered in the discourse of practitioners" (Craig \& Tracy, 1995, p. 267).
} 
procedure" (Chang, see above) contextually constitutes the grounds of reasonable argumentation, or merely implements some general norms of reason constituted elsewhere, it does matter as an indispensable vehicle for making the decision right. (As shown below, even Chang indirectly admits that.)

So, how do we make the decision right without losing the sight of the theories, such as comparativism, which supposedly offer objective normative grounds for the right decision? In particular: Do we need objectively-minded, unbiased arguers or can we count on "good" argumentative processes or procedures in which individual biases cancel each other out?

This is the question I will consider in this paper. To spoil the surprise, I will count myself among those who count on "good" argumentative procedures to answer the question of the grounds of practical reasoning. This is not to deny that good arguers are needed for such procedures, and that argumentation has always an inescapable cognitive aspect which filters out what argumentation eventually becomes, both descriptively and normatively (e.g., Hample, 2005).

I will go about it as follows. Below, in section 2, I will present an extended schema of practical argument I have been developing, which is compatible with the main tenets of comparativism. Further, in section 3, I will argue that the context of well-structured advocacy is an answer to the question of how the rationality of so conceived practical argument can be best squeezed out, or grounded. Finally, in section 4 I will propose a tentative procedure for such a context.

\section{The structure of practical argument}

Take a simple example of practical reasoning stolen from Goodwin:

Assume you are shopping for one of the new-fangled, efficient but expensive light bulbs at your local hardware store. While staring at the one of the multitude of options, you receive this message: "You should buy it—it lasts a lot longer!" This is an argument, and seems potentially relevant to your choice. But it suffers from a fatal vagueness: longer than what? How do you fill in the missing information? (Goodwin, 2013, p. 15)

This, clearly, is a practical argument: it concludes with an action-relevant speech act- "You should buy it": it can be an advice, a recommendation, a call, etc. - rather than a fact-relevant 
assertive (see Lewiński, 2016a). Further, the only argument explicitly given here is a comparative argument: "it lasts a lot longer." We can easily rephrase it in terms of a basic positive comparative fact: Bulb $\mathrm{X}$ is better than $\mathrm{Y}$ with respect to longevity. The crucial unknown here is if we're dealing with a determinate set of alternatives over which we compare, that is, are we in a "well-formed choice situation"? (Chang, 2016, p. 215). We would indeed be, if the comparative "longer than" pertained to "some light bulb that is directly relevant to your decisionperhaps the light bulb you are currently using, or the light bulb of a different manufacturer that is comparable to the one in question in every way except how long it lasts" (Goodwin, 2013 , p. 15). If, by contrast, "longer than" referred vaguely to "some light bulb or other-perhaps longer than one of the manufacturer's cheaper light bulbs, or longer than last year's model" (Ibid.), then we would face a rather vague, suspiciously open set of options, which would eventually make comparisons spurious (cf. "It lasts longer than Edison's first bulb"). In the former case, we are in a position to make a rational choice: all other things being equal, or at least "comparable," longevity might be the decisive, reasonable criterion. In the latter case, due to the illdefined set of alternatives we are prone to lapses in our practical rationality: the comparative fact that the bulb lasts longer than a cheaper type of bulbs which "by definition" last much shorter, cannot reasonably ground our choice. (The fact that the economy class ticket is cheaper than any business class ticket will not help us much in choosing the best economy fare we are looking for. Etc.)

Goodwin's original problem was how to reconstruct the rest of this overly laconic argument. This is no easy undertaking. Yet I can see how this tiny bit of argumentation can - indeed has to - be considered as a part of a much complex schema for practical argumentation. This schema seems to comprehensively grasp all "the missing information" (Goodwin, 2013, p. 15) needed to analyse and evaluate this kind of argument. Below I will present its general elements, using the lightbulb shopping as a running example.

The scheme of practical argument (PA) presented in Figure 1 stems from a rich literature on practical argument in philosophy, Artificial Intelligence, and argumentation theory (see Lewiński, 2015, 2016a for a more detailed discussion). In particular, it is derived from a recent comprehensive account of PA by Fairclough and Fairclough (2012; who themselves are indebted to Atkinson, Bench-Capon, \& McBurney, 2006, and Walton, 2007). While referring to their work for an in-depth 
analysis of all the premises constituting the scheme (Circumstances, Goal, Values), I will briefly mention some basic advantages of the scheme.

Figure 1: The scheme of Practical Argument

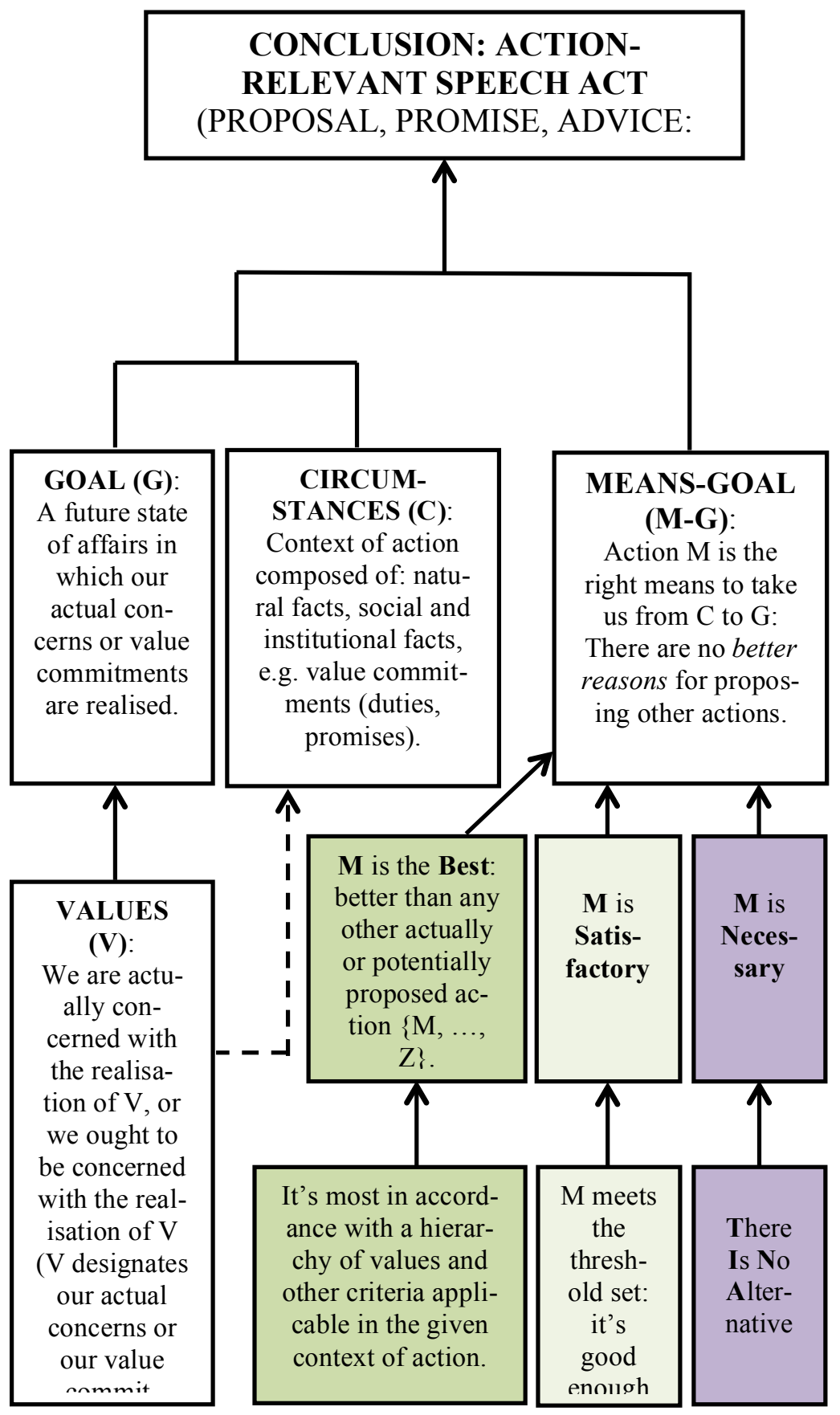

Derived from: Fairclough \& Fairclough (2012) 
Possible, contextually-determined decision criteria: direct or indirect costs and benefits (negative and beneficial consequences / side effects) • opportunity costs • practical feasibility $\bullet$ ethical, moral, or legal implications • likelihood of realization or of success • conformance with other goals or strategies, their timing, duration, or location • (derived from: McBurney, Hitchcock, \& Parsons, 2007, p. 99)

As I have argued before (Lewiński, 2015, 2016a), the scheme distinguishes between context-independent and contextdependent elements of PA. Its basic general structure (as per Fairclough \& Fairclough: all the white boxes in Figure 1) remains constant, while contextual criteria for choosing "the right means" (below the diagram) fluctuate. ${ }^{3}$ It also provides a new account of how to criticise and evaluate PA. It clearly demarcates the attacks on the main premises (Circumstances, Goals, Values, Means-Goals), from those concerning contextdependent decision criteria, and from criticisms of the inference licences related to the type of the inferential step made (necessary, satisfactory, or the best means). Further, the scheme defines its conclusion in terms of a class of action-relevant speech acts, thus pointing to a "unity in diversity" of what we can argue for in PA.

Two other features of the scheme are crucial to the current investigations. First, it clarifies the notion of the means-goal premise. This premise is grounded in one of the three basic inference licences warranting the choice of "the right means" taking us from the current (unwelcome) Circumstances to the (desired) Goals: the means can be necessary, satisfactory (good enough) or simply the best among all the possible, comparable alternatives. (These are mutually exclusive, so we can follow only one of them at a time. See below for elaboration.)

Second, as I will argue below, the scheme shapes the framework of relevance for (multi-party) deliberation where advocacy is instrumental to making a reasonable decision. Typically, different parties argue for the contextual betterness of their proposals for action $\{\mathrm{M}, \mathrm{N}, \mathrm{O} \ldots \mathrm{Z}\}$ (see the "M is the Best" box). Their deliberation develops then as an argumenta-

\footnotetext{
3 Individually, each of these criteria is co-extensive with Chang's (2016) "covering consideration." Taken all together, they constitute the crucial, yet forever elusive, ideal of an evaluation "all things considered" (e.g., Temkin, 2012).
} 
tive polylogue (Lewiński, 2014; Lewiński \& Aakhus, 2014) along the lines of possible disagreements over the various elements of the structure (basic premises, inference rules and contextual criteria).

It is in these two features where comparativism takes hold of our exercise of practical rationality. One of the three paths for justifying the means to be taken ("M is the best") is straightforwardly based on comparison as the principle of reasonable choice. The two other paths are too based on comparisons, but in a less direct way. Realising that a given means is necessary, requires its prior comparison to other-unattainable, inadmissible or inefficient-means, thus leaving this means as the only, hence necessary, alternative for reaching the goal (possibly in conjunction with other means, which can all be individually necessary, but only jointly sufficient). The satisfactory path requires a comparison to a threshold set in advance ("Any bulb of this kind cheaper than $€ 10$ is fine"; more on satisficing below). The model of advocacy-based deliberation I propose below, suggests a reasonable way to do it, to engage in exhaustive and critically justified comparisons. I say "suggests" to acknowledge the possible leap in the dark between making the decision right to making the right decision. Before moving on to this crucial point, I will say something about the possible paths for justifying the choice of "the right" means.

As I argued before (Lewiński, 2015), the simplest formulation of the scheme of practical reason does not really work, due to its incomplete take on the means-goal premise. The basic scheme of practical reason discussed in philosophy and argumentation theory looks more or less like this:
Let's do $X$ !
(Conclusion)
because
$X$ leads to $Y$.
(Means-Goal premise)
and
$Y$ is our desired goal.
(Goal premise)

That this scheme does not quite capture the rationality of PA can be shown by producing arguments that clearly follow the scheme but are not so clearly rational:

Let's stop feeding our children!

because

This will save us lots of money. and

We really need to start saving. 
Here, from acceptable premises (the Goal of saving money is morally acceptable; the Means-Goal relation between stopping feeding children and saving money is technically speaking correct in many contexts) we get a highly objectionable conclusion. That means that there is a problem with the validity of the practical inference drawn here - and thus with the simple scheme in general. What is missing is the "inference licence" regarding the quality of the link between the desired goal (premise) and the proposed means of action (conclusion). The Means-Goal inference needs to be thickened beyond asserting simple causality: " $X$ leads to $Y$."

One obvious option is to take $\mathrm{X}$ as a means necessary to reach $Y$. Whenever we want to achieve $Y$, we have to do X. An exception occurs when $\mathrm{X}$ involves an objectionable (morally unacceptable, too expensive) action, in which case we should abandon our goal. ${ }^{4}$

While being the philosophers' favourite, the necessary means is something of a laboratory case. It is appealing, for it allows to construe the practical inference as modus ponens which makes it valid by standards of classic deductive logic ("If we want $Y$, then only by means of $X$; and we do want Y; ergo, we need to do $X$ "). Yet, in real life, we often have several alternative ways of reaching the goal. Each of these alternatives is typically considered as a sufficient means, an action that in itself is sufficient to take one from the current state of affairs to the desired goal. The choice between available alternatives in PA was recognised already by Aristotle, who famously declared that if the desired end "seems to be produced by several means they [deliberators] consider by which it is most easily and best produced" (Nicomachean Ethics, 1112b12-15). Unsurprisingly, in practical philosophy there is a long tradition of investigating what the "most easily and best produced" means might be. Briefly, when reasoning or arguing over the Means to produce our Goals, we can licence our inference through one of the two basic strategies (see Byron, 1998, 2004): ${ }^{5}$

\footnotetext{
4 "Who wills the end, wills (so far as reason has a decisive influence on his actions) also the means which are indispensably necessary and in his power" (Kant, Groundwork of the Metaphysics of Morals, pp. 80-81; cited in Broome, 2013, p. 159). Indeed, the necessity of means is typically considered the paradigmatic type of inference licence in practical reason (Broome, 2013; Walton, 2007).

${ }^{5}$ We need such a "material" licence, if only because the simple scheme for means other than necessary is formally invalid - it is based on the fallacy of affirming the consequent: If $p$ leads to $q$, and we desire (ought to) $q$, then we should do $p: p \rightarrow q$, $q$, so $p$ (e.g., Searle, 2001, p. 244).
} 
A) Going for "the best": optimising / maximising. What "the best" is, is typically contextually determined, sometimes loosely (when deciding on the best place to take summer holidays), sometimes in a very strict, administratively defined way (when deciding on the best public procurement offer, or best job or grant application). While the general criteria or parameters for selecting the best course of action can be suggested (see the bottom of Figure 1, also: Hitchcock, 2011; McBurney et al., 2007), their exact set, scope, precision and weight depend on the context and cannot be pre-defined. Therefore, they constitute the fluctuating conditions in the scheme of PA. One can, however, distinguish between simple and subtle optimising:

i. Simple optimising applies when deliberators deal with a "static context," that is, when the set of alternative options (means of action) is finite and known (Byron, 1998; this is what Chang, 2016, calls a "well-formed choice situation"): we should simply take the best (most efficient, beautiful, heavy-duty, cheapest) bulb from the display panel in the shop.

ii. Subtle optimising takes place when we are facing an ever-changing "dynamic context" in which the set of options is open-ended and constantly updated (Byron, 1998): Shall we buy the 2016 Philips bulbs or wait a little for the 2017 Samsung line? What better offers can we get in the near future? Such risky questions (Hamblin, 1970, p. 216) call for an on-going calculation of costs and benefits under uncertainty.

B) Going for the "good enough": satisficing by setting a threshold which will fulfil our basic criteria: "Any 10 Watt or less LED bulb for less than $€ 10$ is fine." This, of course, is not the "best way all things considered" but it is an important and reasonable way to licence conclusions of our PA under many typical circumstances:

i. In dynamic contexts, satisficing lets us "economise" on resource-intensive subtle optimising, which requires constant updates and cost-benefit 
analysis. (This plays to the "we are cognitive misers" argument discussed below.)

ii. In static contexts, it allows for global optimisation by letting us being somewhat "easy" on less important local results: "Just take the $€ 9.99$ Philips and let's go, we have plenty of other things to do."

In these ways, satisficing also falls under the "no better reasons" principle (see the Means-Goal box in Figure 1). In dynamic contexts, we (so far) have no better option than the one which first meets the threshold. In static contexts, while locally merely satisficing, we might be optimising in terms of the bigger plan. ${ }^{6}$

The basic inference licence in PA is then: there are no better reasons for proposing other courses of action. ${ }^{7}$ Only when strengthened with this principle is the " $X$ leads to $Y$ " MeansGoal premise properly licenced and the entire PA generates reasonable, even if expectedly defeasible, results. ${ }^{8}$

Apart from necessary and sufficient (either satisfactory or best) means, there is still one more option, which is likely the most common and the least discussed kind of means we consider in our PA. I call them conducive means in order to convey their presumed worthiness in approaching the desired Goal, despite their being neither necessary nor sufficient means. Conducive means should be considered against a disjunction of other alternatives (for they are not necessary) and in conjunction with other means (for they are not sufficient). Examples of such means are plenty: "In order to cut household spending I should

\footnotetext{
${ }^{6}$ For similar reasons, it has been argued (e.g. Byron, 1998) that satisficing is eventually a species of optimisation, as it aims at finding the optimal balance between overall costs (effort, time, other resources) and benefits (satisfaction of preferences and values) of our actions.

${ }^{7}$ Chang (2016, p. 231ff.) criticises this way of defining rational choicewhich she calls "maximalism" - on the account that it is based on a negative ("no better reasons," "not worse") rather than a positive comparative fact ("better than," "equal to"). However, with some uncontroversial additional assumptions ("not worse iff better than or equal to"), both views are compatible in this respect.

${ }^{8}$ Van Eemeren (2016, pp. 17-18) treats the comparison of alternative options for action as a contextually contingent extension of the basic scheme of practical (or: pragmatic) argumentation. The basic scheme relies on the simple "X leads to positive result Y" premise, in general deemed sufficient to warrant the inference. But it is hard to imagine a context where a comparison of alternative routes for getting to the goal is not relevant. Of course, in the case of necessary means - by definition - there exist no alternatives; and in the case of satisficing we can simply compare to the threshold set. Yet, as argued before, both these options are but special cases of comparative reasoning, rather than the other way round.
} 
buy some new energy-saving LED lightbulbs." Clearly, LED lightbulbs are not a necessary means to save money. Instead, I can quit smoking, stop buying books I'll never read, or find a Portuguese girlfriend rather than pay for expensive private classes of Portuguese. Likewise, it is not a sufficient means: alone, even super-efficient LED bulbs will not save me all that much. Still, when supported with other premises of the scheme of PA, and as part of a bigger plan, buying a set of new energy-saving and long-lasting bulbs for the entire house might be not a bad conclusion at all. It might be more efficient, or less painful or troublesome than quitting smoking, books, and my current girlfriend. Or it might just save me per annum the sum I'm looking to save. Shortly, whether because it is an optimal or a satisfactory means, it takes us some way from current Circumstances to the Goal and is thus presumably reasonable.

Following all this, we arrive at the following types of inferences licencing our PA:

a) Doing $X$ is necessary to get to $Y$

b) Doing $X$ is sufficient (and best / good enough way) to get to $Y$

c) Doing $X$ is conducive (and best / good enough way) to get to $Y$

\section{Two basic ways to design practical argumentation}

\subsection{Solo reasoning vs. collective argumentation}

Traditionally, there are at least two views on how we produce the practical argument, both traceable to Aristotle. In general, Aristotle's view that we should go for the "most easily and best produced" means (Nicomachean Ethics, 1112b15) can be considered an early version of comparativism. Our choice of the right means, as evidenced in these passages being a part of the Nicomachean Ethics, can in the first place be understood in terms of an individual cognitive-ethical process. An agent needs to possess certain intellectual and ethical virtues to be able to fully exercise his practical reason, not least phronesis, practical wisdom. In today's language, we would say that an arguer is reasonable in virtue of being open-minded, critical, unbiased, knowledgeable (etc.). Diligent development and exercise of these qualities is what makes the use of practical reason potentially reasonable, as reasonable as it gets for the human scale. If this is all right, then "solo reasoning by a single agent" embodies the 
model of practical reasoning in its purity (Hitchcock, 2011). This is the first view on where to search for the normative grounds of practical reasoning.

However, Aristotle prefaces his proto-comparativism with a telling disclaimer: "We call in others to aid us in deliberation on important questions, distrusting ourselves as not being equal to deciding" (Nicomachean Ethics, 1112b11). To those seeking the path to rationality in an undisturbed, clear and distinct individual mind, this is puzzling. But not to all. Dascal argues that Aristotle was deliberately vague on the distinction between private (internal) and public (collective) deliberation as chief activities of practical reason, in order to expose "a deep analogy between his conceptions of the two domains" (Dascal, 2005, p. 52). Moreover, an individualistic approach to practical argument runs the risk of being "solipsistic, egoistic and anti-social" (Hitchcock, 2002), so the grounds of practical argument are best found in dialogical practices of argumentation where collective values, goals, and institutions are duly considered in a critical argumentative discussion. ${ }^{9}$ When we distrust ourselves on the rationality of our decisions, we then better resort to some critical, and thus corrective, exchange with others. This is the second view.

A number of arguments give substance to the claim that the way to get to a reasonable decision based on a critically tested practical argument, is to put it to the test of collective deliberation where arguers act as advocates of the possible alternatives. Several vivid metaphors have been in circulation to make this point.

One is that of a council. Dascal quotes a passage from Stuart Hampshire, where Aristotle's vagueness, perhaps continuity, between the internal (individual) and external (collective) deliberation is portrayed in terms of a mind as "a council chamber, in which the agent's contrary interests are represented around the table, each speaking for itself" (Hampshire, 1991, p. 51 as quoted in Dascal, 2005, p. 70, n. 13). The "council members" thus advocate for "their" interests which are contrary to "other members"" interests before "the chairman"- the will. We can presume that having heard the best arguments made for each

\footnotetext{
${ }^{9}$ Yes, these two ideas come from the same author-David Hitchcockalthough they are expressed in a somewhat different intellectual context: the collective view (2002) transpires from a critical commentary on Pollock's concept of practical reason for an automated agent, while the individualistic view (2011) itself tries to establish a simple model of instrumental rationality for artificial intelligence.
} 
member's interests, the chairman gains enough insight to issue a reasoned decision to be acted on.

Perelman \& Olbrechts-Tyteca take up similar imagery and claim not only simple similarity between public and private deliberation but rather primacy of the former over the latter:

[...] inward deliberation [...] appears to be constructed on the model of deliberation with others. Hence, we must expect to find carried over to this inner deliberation most of the problems associated with the conditions necessary for discussion with others. [...] Accordingly, from our point of view, it is by analyzing argumentation addressed to others that we can best understand self-deliberation, and not vice versa. $(1969$, pp. 14, 41)

The same point is elaborately defended in Billig's (1996) rhetorical approach to social psychology. His chief polemic point is to argue "against those cognitive theories of thinking, which tend to treat thinking as if it were the silent, internal processing of information" (p. 2). Billig's task is to redefine some basic concepts of cognitive psychology through a $180^{\circ}$ turn:

Thinking is a form of internal argument, modelled on outward dialogue; attitudes are rhetorical stances in matters of controversy; justification and criticism are key rhetorical activities; and so on. [...] An argument for an issue of controversy is also an argument against counterviews. Any reasoned argument seeks to exclude, or persuade against, counter-arguments. (Billig, 1996, p. 2; emphasis in original)

This sounds familiar enough to rhetoricians and dialecticians who approach argumentation as a communicative process, procedure or transaction (Wenzel, 1990; Goodwin, 2005). It's also not uncommon among dialogically minded formal logicians (Dutilh Novaes, 2015; Krabbe, 2013; MacKenzie, 1989). As it turns out, mutual relations between argumentative discussion and solo reasoning might be more pervasive than officially affirmed (Lewiński, in press).

Indeed, as we have seen with the case of Chang's approach, external considerations of deliberative procedures are far-removed from the core of the matter, the very grounds of the reasonable. Yet, little cracks where argumentation scholars can stick their fingers in, do appear. Consider Chang's picture of how the rationality of practical reason is grounded: 
According to comparativism, alternatives must "do battle" in the arena of reasons. Whichever alternatives emerge as victors can be rationally chosen. Or less violently: the alternatives "meet and discuss" which of them will go forth into the world of intention and action. The ones that go forward as a result of that discussion can be rationally chosen. [...] In short, comparativism holds that what makes a choice rational is some achievement, a stamp of approval, a gold star. (Chang, 2016, p. 234).

Despite Chang's disclaimers, we are thus back to Hampshire's metaphor of a reasoning mind as a council chamber in session. The vehicle or source of this metaphor, in line with Perelman \& Olbrechts-Tyteca's (et al.'s) argument, is the actual battle or discussion in a council, which thus takes precedence over the internal practical reasoning of an individual, the target concept. In this externalised sense, the battle of alternatives or a discussion over them are procedures or designs for argumentation. They can take two different shapes: one closer to the discussion, another closer to the battle. This, also, is no news to argumentation scholars.

\subsection{Issue-based deliberation vs. role-based advocacy}

How can we reasonably compare alternatives and decide on the best one through collective practical argumentation? There are, of course, hundreds of ways to do it, but two broad ways have been distinguished.

I have described one of them as an issue-based dialectics (Lewiński, 2016b). A well-known historical precedence is Cicero's argumentum in utramque partem aimed at a "balanced consideration of alternatives" (Schofield, 2008, p. 64). Today, Walton and others would call it a deliberation dialogue (Walton \& Krabbe, 1995, ch. 3; Walton, 1998, ch. 6; McBurney, Hitchcock, \& Parsons, 2007; Atkinson, Bench-Capon, \& Walton, 2013). Blair (2016), capturing a similar concept, brands it as inquiry (while also pondering exploration and discovery).

The basic idea is this: on every issue there are two sidespro and con. Hence, to properly examine or decide on an issue is to juxtapose opposing arguments for and against it. Discussing many options on an issue amounts to pooling all possible pro and con arguments on each option, based on its internal merits (that is, without necessarily comparing it to other options in the first place). The basic assumption is that a deliberative discussion starts with an open problem. The "openness" of the problem means that discussants do not enter deliberation with a de- 
fined position on it and that they do not defend the superiority of "their" position by making a case, that is, by advancing arguments that consistently support the position. Rather, each participant is supposed to give pro and con reasons on each possible solution to the open problem, and to welcome the final weighing of reasons without being committed to one "best" option all along (see Figure 2).

Figure 2: Issue-based weighing of pros and cons

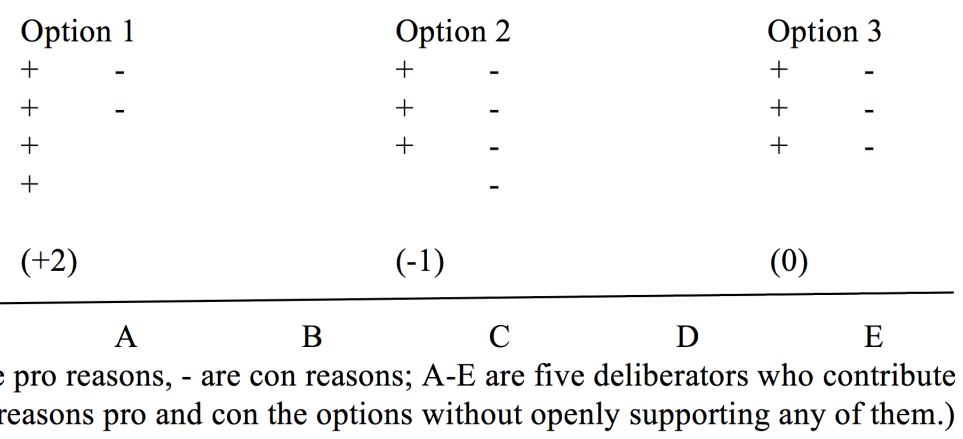

The second approach to collective deliberations can instead be called role-based dialectics, since it sees multi-party deliberation as a clash between arguers fulfilling their dialectical roles, or personae (Lewiński, 2016b). The most famous historical example are Socratic dialogues, where each interlocutor defends his own case in order to convince others of it, while trying to catch them on an inconsistency or other fault (Schofield, 2008). With all due theoretical differences acknowledged, this is what Walton et al. call a persuasion dialogue (Walton \& Krabbe, 1995, chs. 3-4; Walton, 1998, ch. 2; Prakken, 2009; Atkinson, Bench-Capon, \& Walton, 2013), pragma-dialecticians a critical discussion (van Eemeren \& Grootendorst, 2004), and Blair (2016) simply advocacy. The basic commonality is this: one role (protagonist, proponent) amounts to consistently upholding a position against possible opposing positions and critical questioning of the bearers of the other role (antagonists, opponents). Arguments are thus co-defined with dialectical roles of argumentative parties, rather than with dialectical issues detached from any recognisable advocates (see Figure 3). Arguers' task is to make a strong and consistent "case" in the sense of marshalling arguments that support "their" position, doing away with doubts, and rebutting criticisms. This, necessarily, involves constant comparisons with other positions and cases. To use Atkinson et al.'s expression - in what they theorise as persua- 
sion dialogues over actions-positions and arguments are "owned" or "championed" by discussants. By contrast, in deliberation dialogues - which exemplify an issue-based approach"there should be no 'ownership' of options" (Atkinson et al., 2013, p. 123).

Deliberation understood as a role-based exchange is a decision-making activity in which positions are clearly defined and explicitly advocated by given parties, who need to be mindful all along to remain consistent in their argumentative commitments. ${ }^{10}$ The goal is to select, upon critical examination, "the best" of these positions. " There are thus "winners" and "losers."

Figure 3: Role-based clash of contrary positions

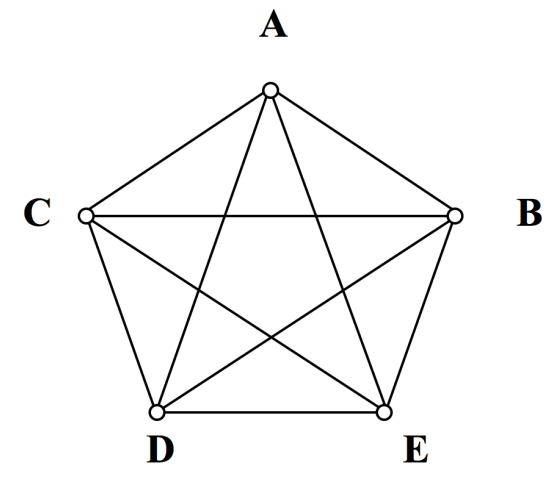

\section{Advocacy-based model for practical argumentation}

\subsection{To inquire or to advocate?}

Which way should we go, then? Goodwin suggests that informal logicians will in general be suspicious of advocacy, on the account that for epistemic argumentative jobs it "will be taken as biased, irrelevant and possibly even fallacious" (2013, p. 2). An example of this is Blair, who advocates against the advocacy model and for the inquiry, largely based on his personal experience. He recalls “meetings when members' advocacy argumen-

\footnotetext{
${ }^{10}$ By contrast, in issue-based activities, participants can be inconsistent, as they are allowed-even expected or obligated! - to advance pro and con arguments for each alternative, criticise and retract the arguments they suggested, and freely change their mind regarding each alternative.

${ }^{11}$ In the longer perspective, argumentative testing of positions might also pave the way for (an) entirely new position(s) to emerge, through a dialectical synthesis of sorts.
} 
tation produced or reinforced divisions in the group and blocked opportunities for open-minded investigations of alternatives" (Blair, 2016, p. 53). However, Grasso's smart response to Blair's paper strongly suggests that properly, "systematically" designed argumentative models of inquiry (discovery) and advocacy would yield "almost indistinguishable results": both "would require a comprehensive and exhaustive exploration of all possibilities: all options are considered in the discovery process, all voices are heard in the advocacy process" (Grasso, 2016, p. 71). Assuming that she is right, the issue then is that of a proper argumentation design (Aakhus \& Jackson, 2005; Jackson, 2015).

But there are reasons tilting the solution towards advocacy. Blair himself mentions that this is how most groups argue by default, whether by adopting explicit rules of order for advocacy (such as Robert's Rules of Order) or simply because quickly enough "the pro and con advocacy begins" in typical group meetings (Blair, 2016, p. 60). A good normative pragmatic designer would surely take this into account-rather than go against this "natural" tendency.

Anecdotal empirical evidence aside, there are important theoretical reasons to try to model practical argumentation in terms of advocacy. To start with, decisions where various voices are heard through advocacy easier gain the crucial facet of democratic legitimacy when compared to decisions somewhat abstractly (or even paternalistically), "rationally considered" in detachment from actual parties claiming stake in the issue (Benhabib, 1994). Further, advocacy might aid us in being cognitive misers; it allows us "to outsource some of the time-consuming and wearisome activity of reasoning to someone who is zealous about it" (Goodwin, 2013, p. 16). This view has been forcefully argued for by Mercier \& Sperber (2011) in terms of the division of cognitive labor under the conditions of the well-known confirmation bias:

When a group has to solve a problem, it is much more efficient if each individual looks mostly for arguments supporting a given solution. They can then present these arguments to the group, to be tested by the other members. This method will work as long as people can be swayed by good arguments, and the results reviewed in section 2 show that this is generally the case. This joint dialogic approach is much more efficient than one where each individual on his or her own has to examine all possible solutions carefully. (Mercier \& Sperber, 2011, p. 65) 
In line with this argument, the current literature on dealing with cognitive biases in rational decision-making is increasingly attentive to the design of contexts for argumentation, while growing sceptical of individual cognitive remedies for solo arguers (Kenyon \& Beaulac, 2014).

Within the framework suggested here, it is crucial that advocacy is more readily consistent with comparativism and the model of practical argument presented above. In models of issue-based deliberation $\grave{a}$ la Blair, first the rational pooling of arguments for and against each option takes place - and only once this is done, the options are compared (see also McBurney et al., 2007). Comparisons are thus consequences of arguments - rather than grounds of arguments, as they rationally should be. Following our lightbulb example: The fact that the bulb lasts $10 \%$ longer than some kind of a standard bulb sounds like a pro-argument. But until we have the proper comparison, it remains utterly empty. Do new competitive bulbs last $30 \%$ or $3 \%$ longer? If $30 \%$, then our bulb is a weak contender on this account, and the argument is in fact a con-argument. It is clear, then, that the basic comparative relations (better than, worse than, equally good) operate at the very core of the practical argument in the first place-rather than in the final, postargumentative "summation" (Blair, 2016). In Blair's procedure, they should belong to Task 2: Investigation using arguments, rather than Task 3: Summation and application, where they are now. ${ }^{12}$

${ }^{12}$ In his elaborate account of practical rationality, Temkin (2012) distinguishes between the Internal Aspects View and the Essentially Comparative View on how to rationally ground our choices. His preference goes for the comparative view, with wide-ranging consequences, such as the suspension of the transitivity axiom (so that $X>Y>Z>X$ is a possible reasonable result). Without claiming an exact correspondence with my distinctions proposed in terms of argumentation theory, I cite his explanation of these concepts as yet another important argument for the view I defend here:

"[O]n the Internal Aspects View, how good $A$ is all things considered will be wholly independent of whether $A$ is compared with alternative $B$, alternative $C$, or any other alternative or set of alternatives. Similarly for $B$. Accordingly, once we know $A$ 's all-things-considered score and $B$ 's all-things-considered score, we'll know how they compare all things considered; clearly this ranking, determined as it is solely by $A$ 's and $B$ 's internal features, will be independent of whether or not $A$ and/or $B$ are compared with any other alternative or set of alternatives" (Temkin, 2012, p. 388). By contrast, on the Essentially Comparative View, "the relevance and significance of the factors for determining an outcome's value will vary depending on the alternatives with which it is compared, so that the value of an outcome $X$ might be $n$, when considered by itself, $o$, when its alternative is $Y, p$, when its alternatives are $Y$ and $Z$, and so on. On this view, there is no single fact of the matter represent- 


\subsection{How to advocate in practical argumentation}

One can start thinking of an advocacy procedure for practical argumentation in terms of the existing role-based dialectical models but extended to incorporate the clash of more than just two positions on an issue; in this way, the model will be a model of a polylogue (Lewiński, 2014; Lewiński \& Aakhus, 2014). Such a procedure can be constructed in a largely formal manner or informally, using the extant pragmatically-oriented dialectical approaches as a basic theoretical background. The pragmadialectical model of a critical discussion may be particularly useful in this endeavour as a well-defined normative account of everyday argumentation. It offers a useful heuristic of dividing argumentative discussions into four "dialectical stages": confrontation, opening, argumentation and concluding (van Eemeren \& Grootendorst, 2004, pp. 57ff.). The four stages can define the procedure for multi-party argumentation in general (Lewiński \& Aakhus, 2014), but they can also be crafted to advocacybased deliberation in particular. In the latter case, the scheme of practical argument expounded in section 2 can serve as the pattern of relevance for all argumentative moves in deliberation. What is offered below, are procedural rules and guidelines, without any strong claim regarding their individual normative status and systemic closure.

To start with, the confrontation and opening stages are intertwined, and possibly opening comes analytically first-a marked difference from the pragma-dialectical critical discussion, where confrontation is the first ideal step.

\section{Opening:}

1. What is at stake? What is the issue?

1a. Arrive at a satisfactory representation of Circumstances: the issue to be tackled.

1b. Define the Goals: future desired states of affairs.

1c. Define the Values which justify the goals and, possibly, also shape the perspective on circumstances and constrain the choice of means.

1d. Decide on the basic principle of means selection in case of non-necessary means: optimising or satisficing.

ing how valuable an outcome really is" (Temkin, 2012, p. 229, emphasis in original). 
1e. Decide on the contextually-relevant criteria for realising the values and selecting the optimal or satisfactory means.

Instrumental practical argumentation in a strict sense is one in which these premises are agreed in advance and held constant: so that we argue solely about the means to be adopted. In reality, of course, this hardly ever happens, so argumentation would develop in all these directions. (All these elements would be kicked back and forth between opening and argumentation.)

\section{Confrontation}

Now, given the circumstances, goals, values and criteria, deliberators are in a position to ask:

2. What shall we do (with this issue)?

Or:

2'. What is the best means to take us from the current circumstances to the desired goals? ${ }^{13}$

2a. Examine the nature of the issue:

$2 \mathrm{a}_{1}$. A yes/no question? ("Shall we take the Philips bulb?") $2 \mathrm{a}_{2}$. An alternative question / (safe) Wh-question: the set of relevant alternatives is finite and known to the arguers ("Shall we take Philips, Samsung or Osram bulb?" / "Which of the bulbs from the display panel shall we take?")

$2 \mathrm{a}_{3}$. An open (risky) Wh-question: the set of relevant alternatives is open-ended ("Which of the new lightbulbs shall we buy?")

2b. Gather all the possible proposals: Let us do $m, n, o, \ldots, z$.

Of course, $2 \mathrm{~b}$ and $2 \mathrm{a}_{2}-2 \mathrm{a}_{3}$ are cross-determined.

2c. Determine the nature of proposals: What is the proposal implying?

$2 \mathrm{c}_{1}$. Determine its illocutionary force (Lewiński, 2016a):

1) Strong, with the highest level of commitment when "the proposer must openly commit herself to speak in defense of her resolution" (Kauffeld, 1998, p. 249)

\footnotetext{
${ }^{13}$ I limit myself henceforth to the strategy of optimising, leaving aside the satisficing options.
} 
2) Neutral, when the proponent is committed to the proposal as a serious consideration/option for deliberators: "inducement to tentative consideration" (Kauffeld, 1998, p. 250)

3) Weak, when the proposal is a mere, tentative "suggestion" (as in "brainstorming sessions": McBurney et al., 2007, p. 100, 116; Walton, 2006, pp. 216-217).

Here, as noted above, I am dealing mostly with 1) and 2) situations of advocacy in deliberation. A proponent has thus an obligation to advocate the positions she proposes to take-that is to say, once the proposal (and not merely a suggestion) is made, advocacy is needed. Overall, there seems to be a continuum: from pure brainstorming or "thinking aloud" without strong commitment and with strong cancellability (level 3), to proposing something as a serious consideration (level 2), to strongly defending one's proposal/choice, presumably made upon best prior consideration of an issue (level 1). It might be hard to say where deliberation (as opposed to persuasion or negotiation dialogues) starts and ends, especially when the level of commitment fluctuates over the course of discussion (diachronic variation) and across various participants (synchronic variation). In such cases, any clear-cut demarcating line would be arbitrary (as I think it is in Atkinson et al., 2013 and Walton, 2006). This model thus takes a maximally advocacy-based interpretation of deliberation as a position-defending-and-attacking argumentative activity. Timid arguers are best advised to instead follow Blair's (2016) inquiry model.

$2 \mathrm{c}_{2}$. Determine the proposal's propositional content

1) My position is that means $m$ is necessary If not, then:

2) My position is that means $m$ is sufficient and best. If not, then:

3) My position is that means $m$ is conducive and best.

Having made all this clear, deliberators can move to the third stage:

\section{Argumentation}

At this stage, in strictly instrumental PA, the presuppositions of proposals advocating the necessary or best means (as expressed in the means-goal premise) are debated vis-à-vis the circum- 
stances, goals, values, and contextual criteria defined at the opening stage. In the case of sufficient and conducive means, the presuppositions are precisely the components of the "bestness" of the advocated means; they constitute the sub-premises of the means-goal premise. A proponent of a given option should, depending on contextual constraints, be able to defend any of the qualities of the advocated option (see Figure 1, following McBurney et al., 2007, p. 99): direct or indirect costs and benefits, their opportunity costs, their consequences, their practical feasibility, etc.

The crucial guideline is at this stage is:

3. Construct your main arguments in terms of comparative facts:

Option $m$ is better than $n$ with respect to \{costs and benefits, feasibility, moral / aesthetic values, conformance with other goals or strategies, ...

Eventually, the argumentation stage should return a set of comparative facts, critically tested in the back-and-forth of the competitive argumentative discussion.

\section{Concluding}

This brings us to the problems of concluding the discussion on the basis of the results of argumentative procedures. In a dyadic discussion, this is a fairly straightforward business, since arguers can choose from but two options: that "the protagonist's standpoint is acceptable and the antagonist's doubt must be retracted, or that the standpoint of the protagonist must be retracted" (van Eemeren \& Grootendorst, 2004, p. 61). Such a limitation to duality is an all-too-common trick in the literature (see Lewiński \& Aakhus, 2014 for an overview). Witness Chang's strategy who, upfront, declares that: "To simplify, I will henceforth treat choice situations as involving only two alternatives" (2016, p. 215).

In a multi-party discussion - a polylogue - the choices may be plenty, since by definition there are many protagonists of distinct positions and thus also many distinct antagonists. One alternative can simply be better than any other, which allows for a clear conclusion (the Bingo! case). But some positions can be better on, let us assume, an equal amount of equally important considerations, which possibly leads to a standoff. Arguers may also decide to "sum up" all the conclusions of extracted dyadic arguments through "pairwise comparisons" suggested by Blair 
(2016, p. 66) and Chang. This applies especially in the case where they decide to split their procedure into a sequence of dual pro-et-contra encounters: Shall we do $m$ ? Shall we do $n$ ? Shall we do $o$ ? Dialectically speaking, such local concluding stages seem the most viable option, but the final evaluation of the entire multi-party deliberation may face a number of problems (Lewiński \& Aakhus, 2014). One of them is that more than one such sub-discussion ends with a yes resolution, while only one course of action can be taken. Another is that all options are objectionable for one reason or another, and the end result is nothing but a series of nos. Finally, there is the difficulty mentioned above: if dyads directly compare two proposals (Shall we do $m$ or $n$ ? Etc.), each proposal can be once better and once worse, making it hard to decide on a single "best" option $(m>n$ $>o>m) .{ }^{14}$ Some novel methods of concluding complex polylogues are yet to be developed - especially if the ideal modelling aims at grasping some form of a reasonable "resolution," rather than mere "settling" of deliberations, for instance through voting or preference-aggregation - which, by the way, generate their own well-known issues such as a 50-50 vote or Condorcet cases.

\section{Conclusion}

So where is the reasonableness of practical argument?

It can be grounded in some abstract ideal detached from actual practical argumentation, such as proposed by Chang. Or it can be constituted in practical reasoning or argumentation. In the former case, reasoning or argumentation can better or worse approach the ideal; in the latter it can better or worse ground the ideal. Let us give up the hope of deciding which one is the case. We are still left with the same (meta-theoretical) comparative, normative framework: in both cases we can do it better or worse. Clear and distinct-or: objective and unbiased-solo practical reasoning is one way to do it better, rather than worse. Collective argumentation is another, where we can go for more co-operative inquiry / open deliberation - or for more competitive advocacy / dialectics.

I have argued here that the last option is empirically adequate and theoretically consistent. When properly designed, advocacy becomes what we would consider a reasonable dialectical argument at large: diligent, even zealous, argumentation in

14 For detailed analyses of the conditions for this to happen, see Temkin (2012). 
defence of a contested thesis, yet within the bounds of some mutually recognised rules and constraints (Goodwin, 2013). A victor in such a benevolent battle is then not just some alternative or other, but the rationality itself (that's Aristotle). Even if not exclusively, a rational choice can be the end result of an advocacy procedure.

Acknowledgements: An earlier, shorter version of this paper was presented during the 11th International Conference of the Ontario Society for the Study of Argumentation (OSSA): Argumentation, Objectivity, and Bias, 18-21 May 2016, Windsor, $\mathrm{ON}$, and appeared in the proceedings edited by Patrick Bondy and Laura Benacquista. I would like to thank Jean Goodwin (my OSSA commentator) and the audience for many useful comments and suggestions. This work has been supported by an exploratory grant for international projects, awarded by the Faculty of Social Sciences and Humanities (FCSH), Universidade Nova de Lisboa, as well as a grant of the Portuguese Foundation for Science and Technology (FCT): PTDC/MHC-FIL/0521/2014.

\section{References}

Aakhus, M., \& Jackson, S. (2005). Technology, interaction, and design. In K. Fitch \& R. Sanders (Eds.), Handbook of Language and Social Interaction (pp. 411-436). Mahwah, NJ: Lawrence Erlbaum.

Aristotle. (1984). Nicomachean ethics. In J. Barnes (Ed.), The Complete Works of Aristotle, Vol. II (pp. 1729-1867) (transl. by W. D. Ross \& J. O. Urmson). Princeton, NJ: Princeton University Press.

Atkinson, K., Bench-Capon, T., \& McBurney, P. (2006). Computational representation of practical argument. Synthese, 152(2), 157-206.

Atkinson, K., Bench-Capon, T., \& Walton, D. (2013). Distinctive features of persuasion and deliberation dialogues. Argument and Computation, 4(2), 105-127.

Benhabib, S. (1994). Deliberative rationality and models of democratic legitimacy. Constellations, 1(1), 26-52.

Billig, M. (1996). Arguing and thinking: A rhetorical approach to social psychology. $2^{\text {nd }}$ ed. Cambridge: Cambridge University Press. 
Blair, J. A. (2016). Advocacy vs. inquiry in small-group deliberations. In D. Mohammed \& M. Lewiński (Eds.) (2016). Argumentation and Reasoned Action: Proceedings of the 1st European Conference on Argumentation, Lisbon 2015. Vol. I (pp. 53-68). London: College Publications.

Broome, J. (2013). Rationality through reasoning. Oxford: Blackwell.

Byron, M. (1998). Satisficing and optimality. Ethics, 109(1), 6793.

Byron, M. (Ed.) (2004). Satisficing and maximizing: Moral theorists on practical reason. Cambridge: Cambridge University Press.

Chang, R. (2002). The possibility of parity. Ethics, 112(4), 659688.

Chang, R. (2004). All things considered. Philosophical Perspectives, 18(1), 1-22.

Chang, R. (2016). Comparativism: The grounds of rational choice. In E. Lord \& B. McGuire (Eds.), Weighing reasons (pp. 213-240). Oxford: Oxford University Press.

Craig, R. T., \& Tracy, K. (1995). Grounded practical theory: The case of intellectual discussion. Communication Theory, 5(3), 248-272.

Dascal, M. (2005). Debating with myself and debating with others. In P. Barrotta \& M. Dascal (Eds.), Controversies and subjectivity (pp. 33-73). Amsterdam: John Benjamins.

Dutlih Novaes, C. (2015). A dialogical, multi-agent account of the normativity of logic. Dialectica, 69(4), 587-609.

Eemeren, F. H., van (2016). Identifying argumentative patterns: A vital step in the development of pragma-dialectics. Argumentation, 30(1), 1-23.

Eemeren, F. H., van \& Grootendorst, R. (2004). A systematic theory of argumentation: The pragma-dialectical approach. Cambridge: Cambridge University Press.

Fairclough, I., \& Fairclough, N. (2012). Political discourse analysis. London: Routledge.

Goodwin, J. (2005). The public sphere and the norms of transactional argument. Informal Logic, 25(2), 151-165.

Goodwin, J. (2013). Norms of advocacy. In D. Mohammed \& M. Lewiński (Eds.). Virtues of Argumentation. Proceedings of the 10th International Conference of the Ontario Society for the Study of Argumentation (OSSA), 22-26 May 2013 (pp. 1-18). Windsor, ON: OSSA. 
Grasso, F. (2016). The deliberation and the advocacy rooms: Commentary on Blair's Advocacy vs. inquiry in small-group deliberations. In D. Mohammed \& M. Lewiński (Eds.) (2016). Argumentation and Reasoned Action: Proceedings of the 1st European Conference on Argumentation, Lisbon 2015. Vol. I (pp. 69-73). London: College Publications.

Habermas, J. (1984). The theory of communicative action. Vol. 1: Reason and the rationalization of society (transl. by $\mathrm{T}$. McCarthy). Boston: Beacon.

Hamblin, C. L. (1970). Fallacies. London: Methuen.

Hample, D. (2005). Arguing: Exchanging reasons face to face. Mahwah, NJ: Lawrence Erlbaum.

Hitchcock, D. (2002). Pollock on practical reasoning. Informal Logic, 22(3), 247-256.

Hitchcock, D. (2011). Instrumental rationality. In P. McBurney, I. Rahwan \& S. Parsons (Eds.), Argumentation in MultiAgent Systems: Lecture Notes in Computer Science (pp. 111). Dordrecht: Springer.

Jackson, S. (2015). Design thinking in argumentation theory and practice. Argumentation, 29(3), 243-263.

Kauffeld, F. J. (1998). Presumptions and the distribution of argumentative burdens in acts of proposing and accusing. Argumentation, 12(2), 245-266.

Kenyon, T., \& Beaulac, G. (2014). Critical thinking education and debiasing. Informal Logic, 34(4), 241-263.

Krabbe, E.C.W. (2013). Topical roots of formal dialectic. Argumentation, 27(1), 71-87.

Lewiński, M. (2014). Argumentative polylogues: Beyond dialectical understanding of fallacies. Studies in Logic, Grammar and Rhetoric, 36(1), 193-218.

Lewiński, M. (2015). Practical reasoning and multi-party deliberation: The best, the good enough and the necessary. In B. Garssen, D. Godden, G. Mitchell \& A. F. Snoeck Henkemans (Eds.), The Eighth Conference of the International Society for the Study of Argumentation (ISSA) (pp. 851-862). Amsterdam: SicSat.

Lewiński, M. (2016a). How to conclude practical argument in a multi-party debate: A speech act analysis. In D. Mohammed \& M. Lewiński (Eds.) (2016). Argumentation and Reasoned Action: Proceedings of the 1st European Conference on Argumentation, Lisbon 2015. Vol. I (pp. 403-420). London: College Publications. 
Lewiński, M. (2016b). Dialectics and polylogues: The case of multi-party deliberations. In R. von Burg (Ed.), Dialogues in Argumentation (pp. 105-123). Windsor, ON: Windsor Studies in Argumentation.

Lewiński, M. (in press). Argumentative discussion: The rationality of what? TOPOI: An International Review of Philosophy. Online first, DOI: 10.1007/s11245-015-9361-0.

Lewiński, M., \& Aakhus, M. (2014). Argumentative polylogues in a dialectical framework: A methodological inquiry. Argumentation, 28(2), 161-185.

MacKenzie, J. (1989). Reasoning and logic. Synthese, 79(1), 99117.

McBurney, P., Hitchcock, D., \& Parsons, S. (2007). The eightfold way of deliberation dialogue. International Journal of Intelligent Systems, 22(1), 95-132.

Mercier, H., \& Sperber, D. (2011). Why do humans reason? Arguments for an argumentative theory. Behavioral and Brain Sciences, 34(2), 57-74.

Perelman, Ch., \& Olbrechts-Tyteca, L. (1969). The new rhetoric: A treatise on argumentation (transl. by J. Wilkinson \& $\mathrm{P}$. Weaver). Notre Dame: University of Notre Dame Press. (Original work published 1958.)

Prakken, H. (2009). Models of persuasion dialogue. In I. Rahwan \& G.R. Simari (Eds.), Argumentation in Artificial Intelligence (pp. 281-300). Dordrecht: Springer.

Schofield, M. (2008). Ciceronian dialogue. In S. Goldhill (ed.), The end of dialogue in antiquity (pp. 63-84). Cambridge: Cambridge University Press.

Searle, J. R. (1969). Speech acts: An essay in the philosophy of language. Cambridge: Cambridge University Press.

Searle, J. R. (2001). Rationality in action. Cambridge, MA: MIT Press.

Searle, J. R. (2010). Making the social world: The structure of human civilization. Oxford: Oxford University Press.

Temkin, L. S. (2012). Rethinking the Good: Moral ideals and the nature of practical reasoning. Oxford: Oxford University Press.

Walton, D. (1998). The new dialectic: Conversational contexts of argument. Toronto: University of Toronto Press.

Walton, D. (2006). How to make and defend a proposal in a deliberation dialogue. Artificial Intelligence and Law, 14(3), 177-239.

Walton, D. (2007). Evaluating practical reasoning. Synthese, 157(2), 197-240. 
Walton, D., \& Krabbe, E.C.W. (1995). Commitment in dialogue: Basic concepts of interpersonal reasoning. Albany: State University of New York Press.

Wenzel, J. W. (1990). Three perspectives on argument: Rhetoric, dialectic, logic. In J. Schuetz \& R. Trapp (Eds.), Perspectives on argumentation: Essays in honor of Wayne Brockriede (pp. 9-26). Prospect Heights: Waveland. 